Sparling, D. W., G. Linder, C. A. Bishop, and S. K. Krest. 2010. Ecotoxicology of Amphibians and Reptiles. Second Edition. CRC Press. xxv+916 pp.

ISBN 978-1-4200-6416-2; 18.3×25.6 cm (hardcover) Price: $\$ 159.95$

www.taylorandfrancis.com

www.crcpress.com/www.setc.org

This impressive compendium captures the advances made regarding the status of amphibians and the largely understudied reptiles. The first edition that was produced 10 years ago was stimulated by the emerging awareness of the global decline of amphibians. The editors note that substantial gains have been made in many aspects of ecotoxicology, especially of amphibians during the past decade, yet somewhat surprisingly there was no change in the proportion of studies relative to other vertebrates.

The 18 chapters developed by 30 contributing authors contain 551 pages jammed with relevant citations that anyone from the curious to the dedicated professional can use as a launch point for subsequent conservation or environmental management work involving amphibians or reptiles. The last third of the book (pp. 553-903) contains a compilation of studies of metals in reptiles extracted from an extensive database gleaned from more than 350 references. The book closes with a useful 11-page index.

Although the book clearly builds from the first edition, this update functions as a standalone work. Some preliminary information, such as the introduction to the amphibian-decline phenomenon is summarized and readers interested in developing the full historical context might want to refer to the first edition or seek out the various references cited. The chapters on the general ecotoxicology and physiological ecology of amphibians and reptiles establish a deep appreciation for the unique characteristics of these animals, both in their own right and as important components of ecological systems. Two chapters that do not offer much beyond the

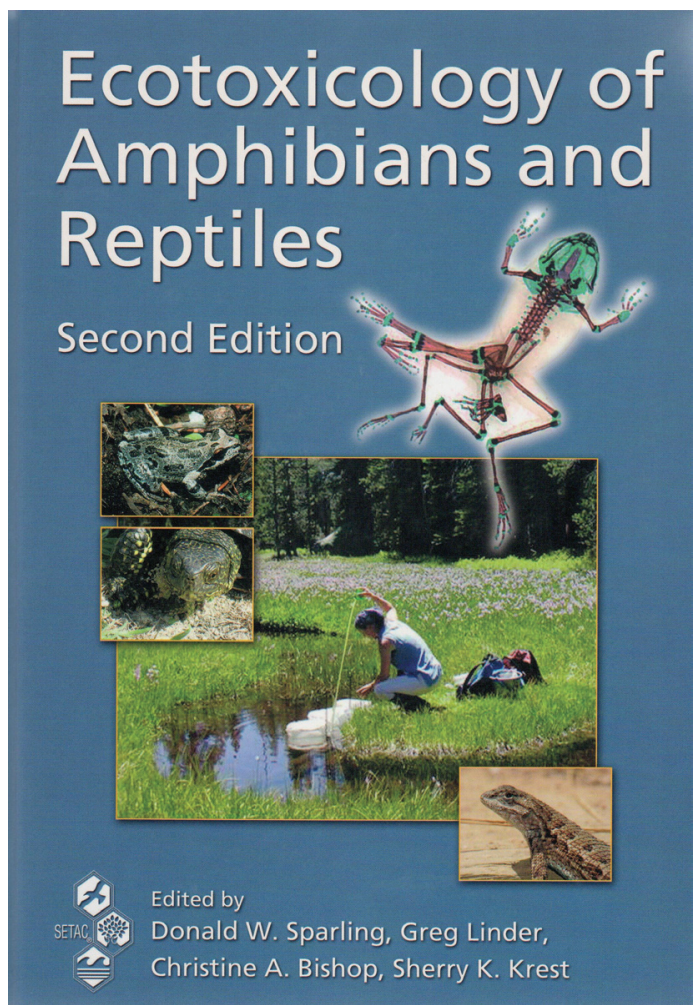

first addition are the chapter on the ecotoxicology of pesticides in reptiles (Chapter 7) acknowledged as being essentially the same as the earlier edition and the chapter on metals in amphibians (Chapter 11).

As with any large work of this nature involving multiple authors, there are editorial challenges with terminology that inevitably slip through. One such example is the use of the terms extinction or local extinction in Chapter 1 even though extirpation is used properly in Chapter 3. In Chapter 2, in discussing a pathogen, the authors state that it is "now endemic," though clearly they mean that it is "now naturalized." The term "heavy metal" is used despite published pleas over three decades to drop this usage, including a recommendation from the International Union of Pure and Applied Chemistry (IUPAC) in 2002 to do so. Also, there are troubling inclusions and apparent recommendations for the use of NOECs 
and LOECs to describe responses to chemicals, despite the dedicated efforts by many to move beyond these very limiting endpoints. And there is the odd entry error such as the total number of amphibian species identified in Table 1.1 as 1800 , but the corresponding text states 1808 . But on the whole, such items are infrequent and do not detract substantively from this excellent scholarly work. Even at the listed price of $\$ 159.95$, this book should be added to the library of anyone working as a risk assessor, manager, or conservation specialist.

\section{Larry Kapustka}

Senior Ecologist and Ecotoxicologist

LK Consultancy

Calgary, Alberta. CANADA

E-mail: Kapustka@shaw.ca. 